\title{
Duties to rescue: individual, professional and institutional
}

doi:10.1136/medethics-2016-103526

Clinicians and researchers can often rescue patients or research participants from serious harms. Indeed, they often have a duty to do so-a duty to rescue. Duties to rescue are frequently discussed in the medical ethics literature, but according to Tina Rulli and Joseph Millum they are under-theorised and more problematic than is normally acknowledged. ${ }^{1}$

Rulli and Millum outline two widely discussed conceptions of rescue duties: a so-called duty of easy rescue, applying to all moral agents (including healthcare professionals), and the rule of rescue, applying specifically to institutions. They raise concerns about both.

\section{THE DUTY OF EASY RESCUE}

The duty of easy rescue is, as its name suggests, a duty to rescue that obtains only where the rescue can be effected at minimal cost to the rescuer. It is normally understood as applying to all individual moral agents, and is perhaps the most frequently discussed duty to rescue. But Rulli and Millum argue that it faces problems.

Chief among these is that it seems at risk of over-extending. Most inhabitants of wealthy nations can easily rescue impoverished people in Africa simply by donating small amounts of money to charity. Does this imply that they each have a duty to rescue each impoverished individual whom they can rescue at minimal cost? There are two potential worries here. One is an epistemic problem-a problem with identifying how far the duty of easy rescue extends. The second is a normative problem-it might seem that if the duty of easy rescue ends up being very broad in scope, then it will in fact be highly demanding. Though the cost of effected any individual rescue that falls under the duty will be low, in aggregate, the costs of fulfilling the duty may be extremely high, and this might be thought to cast doubt on whether there really is such a duty.

\section{THE RULE OF RESCUE}

Rulli and Millum next turn to the so-called rule of rescue. As originally conceived, this was not a normative ethical principle, but a description of a psychological tendency: the "tendency to judge that we ought to rescue identifiable victims, even at great cost" (see page 261) although we have no similar duty to rescue unidentifiable victims. However, as Rulli and Millum note, it has often been invoked as a normative principle. That is, it has been understood to hold not that people generally do rescue identifiable individuals in preference to unidentifiable victims, but that they ought to do so. In medical ethics, it is normally applied in institutional contexts, such as health system-level resource allocation.

The rule of rescue might seem to help with the problems of scope and demandingness. It gives a clear specification of the scope of the strongest duties to rescuethey extend only to cases in which the victim is identifiable - and in restricting the scope of rescue duties in this way, it also somewhat limits the costs of fulfilling these duties. However, Rulli and Millum hold that the rule is blighted by lack of clarity over what 'identifiable' means and argue that once the concept is appropriately clarified, it becomes clear that identifiability has no moral significance.

\section{RE-CONCEPTUALISING RESCUE DUTIES}

Rulli and Millum's positive project is to re-conceptualise rescue duties in a way that renders them both plausible and useful for guiding bioethical decisionmaking. Their main suggestion is that it will be helpful to focus on duties that fall on (i) institutions, and (ii) professionals, as opposed to (iii) ordinary individual moral agents. This focus will, they argue, allow us to at least partially evade the problems of demandingness and scope that they have identified.

\section{THE PROBLEM OF DEMANDINGNESS}

Consider first the issue of demandingness. Regarding institutional duties to rescue, Rulli and Millum note that:

The institutional nature of the duty can ... assuage concerns about its force. Giving absolute priority to people in need of rescue over people with lesser needs would be unfair. Institutions have obligations to all of their members, and

\section{Thomas Douglas, Associate Editor}

so there is some threshold at which an institution should forgo providing a costly rescue to some individual so that it can provide lesser benefits to a larger number of people. A plausible institutional duty of rescue, then, will be limited to cost-effective 'easy' rescues (see page 262).

The thought here is that institutional duties are able to avoid placing excessive burdens on rescuers because they are independently limited by constraints relating to fair distribution.

Rulli and Millum suggest that focusing on professional duties also helps to mitigate concerns about demandingness, though in a different way-they enable us more easily to explain the demands that rescue duties do create:

\begin{abstract}
The existence of these more stringent professional duties to rescue is uncontroversial: they are grounded in the profession's history, an implicit contract with society, and voluntary assumption of the role by the individual professionals. The professional context thereby explains the demanding force of the professional's duty to rescue (see page 263).
\end{abstract}

\section{THE PROBLEM OF SCOPE}

Consider now the problem of scope. Again, Rulli and Millum suggest that focusing on institutional duties may help us evade this problem:

\footnotetext{
[I]nstitutional obligations are not general, they are held to a specific population. As such, the institutional focus can provide guidance on the scope of a duty to rescue. Where with the individual duty to rescue it was unclear why an agent would have a duty to rescue some specific person rather than another in similar need, an institutional focus prioritises individuals for which an institution is responsible. Despite the great amount of need in the world, institutions have primary responsibility to address the needs of their own constituents (see page 262).
}

Similarly, they suggest, professional duties have a clearer scope than the duties to rescue falling on ordinary individual moral agents, since professional norms generally include an assignment of duties owed to specific groups of people: 
The professional context is also relevant to the duty's scope. For example, doctors have special obligations to their patients that justify partiality to these patients over others. More generally, professionals must take on greater costs to perform rescues within their area of expertise than outside it. Doctors have more demanding duties to rescue the sick and injured than people who are drowning (see page 263).

\section{SOME CRITICAL THOUGHTS}

Rulli and Millum make many excellent points and I believe their paper will (and certainly ought to) serve as a point of departure for future discussions of rescue duties in medicine and medical research. However, I wish to end by raising some concerns about their proposal. Some of these concerns are acknowledged by the authors, and none undermine the main messages of their paper. However they do collectively suggest that that the path forward for the theorist of rescue duties may be a thorny one.

An initial point is that it is not clear that all of the virtues of Rulli and Millum's institutional-professional approach are really advantages of that approach; a theorist who wishes to focus on ordinary individual moral duties may be able to avail herself of some of the same strategies that Rulli and Millum adopt for evading the problems of scope and demandingness.

For example, Rulli and Millum suggest that institutional rescue duties may be limited by the fact that institutions have obligations of fairness which prevent them from giving absolute priority to potential rescue victims vis a vis people in lesser need. But it is not obvious that individual moral agents (including those acting outside professional roles) lack such duties. Suppose I decide to donate money to an African charity fighting worm-borne diseases in children. But suppose I specify that my donation must support only treatment for male children. There is arguably something defective about my action in this case, a plausible explanation of this would hold that I violate a duty of fairness. Fairness requires that $\mathrm{I}$ not discriminate against female children in this way. But it seems difficult to conceive of this requirement as an institutional or professional moral norm, for in this case I appear to be acting as a private individual.

My second point concerns the degree to which invoking institutional and professional duties to rescue really enables us to avoid the problem of demandingness. The duties to rescue that fall on institutions and professionals may be limited in all of the ways that Rulli and Millum suggest. They may thus be relatively undemanding. But, as the authors acknowledge, these duties are additional to, not replacements for, ordinary individual duties to rescue. Individuals fulfilling professional roles and acting within institutional structures also have duties that fall on them simply by virtue of their being moral agents. And if these individual moral duties are highly demanding, the relative undemandingness of any additional institutional and professional duties will provide little solace.

Of course, there is an indirect way in which acknowledgement of institutional and professional duties to rescue may substantially diminish the demandingness of individual duties to rescue. If institutions and professionals fulfil their duties to rescue, then perhaps there will be little rescuing left for ordinary individuals to do. But it is not clear that this is so. Rulli and Millum note that, under an unjust institutional scheme, there may be great unmet health needs and there may thus remain much work for individual 'rescuers' to do. But arguably even in a world where institutions and professionals behave justly_including by fulfilling all of their duties to rescue-there will remain many unment health needs and thus many opportunities for rescue by individuals.

My final comment concerns the problem of scope. Again, it is not clear to what extent a focus on institutional and professional duties allows us to evade this problem. And again, this is because institutional and professional duties to rescue are additional to ordinary individual duties to rescue. This means that, even if the scope of institutional and professional duties to rescue were clear, there would remain a need to determine the scope of individual duties to rescue.

Moreover, there is one way in which the addition of institutional and professional duties into the frame creates new epistemic problems: now we must ask questions about how duties to rescue distribute across institutions, professionals and ordinary individuals. For instance, we must ask to what extent healthcare resource allocation is a task for health systems and to what extent it is a task for individual health professionals (as in 'beside rationing' approaches).

\section{AN EFFICIENT DIVISION OF MORAL LABOUR}

Rulli and Millum are perhaps acknowledging these complications when they note that "the relationship between institutional and professional duties to rescue is a rich area for future study by bioethicists" (see page 263) and that there is a need for a "foundational justification for individual duties to rescue that can specify their scope and force" (see page 263).

One helpful approach to questions regarding the distribution of duties to rescue may be the idea of an 'efficient division of moral labour'-the idea that the correct distribution of moral obligations across different individuals and institutions is the one that most efficiently realises our moral objectives. This will often involve attributing different moral obligations to different individuals and institutions. For instance, John Rawls famously (and controversially) argued that objectives of justice can most efficiently be realised by assigning obligations of justice primarily to a society's basic institutional structure while private individuals are for the most part left free to pursue their own ends. ${ }^{2}$ Similarly, it might be thought that the goals of medicine can most efficiently be achieved by, for example, assigning obligations to consider budgetary considerations to healthcare systems, while individual clinicians are instead primarily assigned obligations to maximise the health of their own patients.

Of course, even if the idea of an efficient division of moral labour is helpful, it is not self-evident what the most efficient distribution of medical rescue duties is. This is, I think, another rich area for future study by bioethicists.

\section{REFERENCES}

1 Rulli T, Millum J. Rescuing the duty to rescue. J Med Ethics 2016;42:260-4.

2 Rawls J. Political liberalism. New York: Columbia University Press, 1993:268-9. 